\title{
Simulated Analysis of the Mixing Performance of Jet-mixing Apparatus
}

\author{
Jing Ma ${ }^{1 a}$, Baijing Qiu ${ }^{1 b}$, Run Yan ${ }^{2 c}$ \\ ${ }^{1}$ Key Laboratory of Modern Agricultural Equipment and Technology, Ministry of Education and \\ Jiangsu Province, Jiangsu University, Zhenjiang 212013, China \\ 2 Jiangsu Polytechnic College of Agriculture and Forestry, Zhenjiang 212013, China

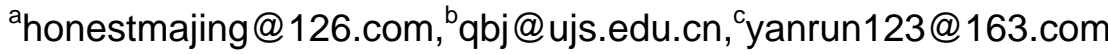

Keywords: mixing, jet-mixing apparatus, Computational Fluid Dynamics, area ratios

\begin{abstract}
In order to determine the parameters of mixing experiment with jet-mixing apparatus, 3 outlet diameters of jet-nozzle $d$ and 5 area ratios $m$ were selected to import the computer based on Computational Fluid Dynamics ( CFD ) to simulate the real mixing experiment. The results show that, in the real experiment of jet-mixing apparatus not only to consider the effect of area ratio but also to consider the effect of outlet diameter of jet-nozzle. The wasted energy of jet-nozzle also had a large proportion in the mixing performance of jet-mixing apparatus.
\end{abstract}

\section{Introduction}

Most of traditional machinery for plant protection using artificial pre-mixing, which have to fore-mix the spray pesticides and water together at a large vessel and then uniform the mixing liquid. Operator has to contact with pesticides directly, and may be harmed. In recent years, with the development and application of large machinery for plant protection, will be separated from the medicine chest and tank, realize the potion separation, online mixing which can save pesticide and reduce cost and pollution is the development trend[1-3]. Jet-mixing device is the key component of online mixing, its performance directly affects the mixing effect. Therefore, the simulated analysis of the mixing performance of jet-mixing apparatus that can provide the theoretical basis has an important value to the real tests.

From the current researches about the performance and structure of jet mixing apparatus, they didn't consider the effect of jet mixing apparatus. In order to solve these problems, Chen Zhigang et al. realized an accuracy and intelligent control on pesticide concentration in the process, and an advanced control system was developed[4]. He Peijie chose different jet nozzle diameters and different jet nozzle distances and some other parameters to determine the pressure ratio and the flow ratio of jet-mixing apparatus[5]. Li Yanglin et al. proposed bipolar jet mixing device and studied the pressure ratio and mixing ratio experimentally, but he didn't provide the corresponding mathematics model[6]. To research the influence of working state of on-line mixing spray system using a jet-mixing apparatus as the core component, Qiu Baijing et al. based on spectrophotometric method, and the mixing solution of on-line mixing spray system were collected, and the collected samples were measured to characterize the mixing uniformity of the pesticide and water[7]. Meanwhile, to analyze and compare the mixing performance of different kinds of jet mixing apparatus, $\mathrm{Xu}$ Youlin designed 4 forms of jet-mixing apparatus and carried out numerical simulation by using CFD software Fluent flow[8].

Because of the characteristics of jet-mixing apparatus' structure, the pressure was an important parameter to evaluate the mixing effect of jet-mixing apparatus. And many researchers devote themselves to study that reducing pressure loss to improve the mixing effect of jet-mixer. This text applied CFD to simulated analysis on the structural parameters of jet-mixer, in order to provide a theoretical basis for the real test.

\section{Structure and parameters of jet-mixing apparatus}

A jet-mixing apparatus is mainly composed of jet nozzle, medicine sucking mouth, suction 
chamber, mixing tube and diffusion tube, its structure is schematically shown in figure 1 . And the structural parameters of jet-mixing apparatus could be divided into fixed parameters and variable parameters, fixed parameter is a constant parameter in the optimization design and variable parameter refers to changing parameters values in order to explore an optimized parameter in the effects of flow jet to jet-mixing apparatus in simulation design. The specific classification is shown in table 1.

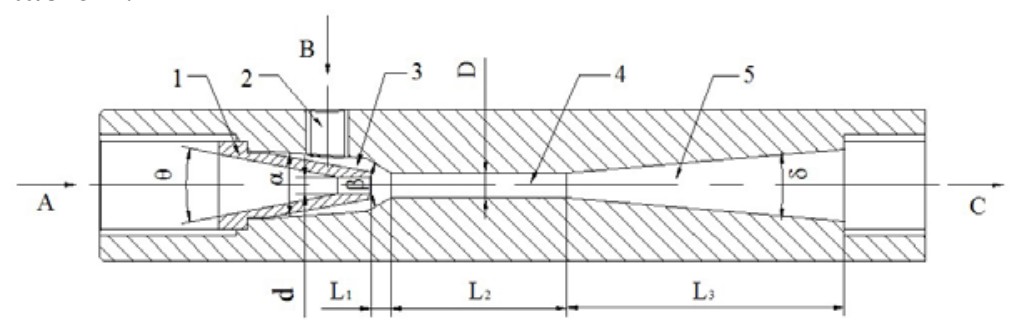

1.jet nozzle 2.medicine sucking mouth 3.suction chamber 4.mixing tube 5.diffusion tube

Fig.1 Schematic of jet-mixing apparatus

Table 1 Classification of structure parameters of jet-mixing apparatus

\begin{tabular}{|c|c|c|c|}
\hline $\begin{array}{l}\text { Parameter } \\
\text { type }\end{array}$ & Structure parameters & $\begin{array}{l}\text { Symbol } \\
\text { s and } \\
\text { units }\end{array}$ & $\begin{array}{l}\text { Valu } \\
\text { e }\end{array}$ \\
\hline \multirow{2}{*}{$\begin{array}{l}\text { Variable } \\
\text { parameter }\end{array}$} & $\begin{array}{l}\text { Diameter of the export of jet } \\
\text { nozzle }\end{array}$ & $d / \mathrm{mm}$ & \\
\hline & Diameter of mixing tube & $D / \mathrm{mm}$ & \\
\hline \multirow{7}{*}{$\begin{array}{c}\text { Fixed } \\
\text { parameter }\end{array}$} & Angle of suction chamber & $\alpha /^{\circ}$ & 10.0 \\
\hline & $\begin{array}{l}\text { Entrance angle of mixing } \\
\text { tube }\end{array}$ & $\beta /^{\circ}$ & 60.0 \\
\hline & $\begin{array}{l}\text { Convergence angle of jet } \\
\text { nozzle }\end{array}$ & $\theta /^{\circ}$ & 16.0 \\
\hline & Nozzle spacing & $L_{1} / \mathrm{mm}$ & 4.5 \\
\hline & Length of mixing tube & $L_{2} / \mathrm{mm}$ & 36.0 \\
\hline & $\begin{array}{l}\text { Diffusion angle of diffusion } \\
\text { tube }\end{array}$ & $\delta /{ }^{\circ}$ & 9.0 \\
\hline & Length of diffusion tube & $L_{3} / \mathrm{mm}$ & 35.0 \\
\hline
\end{tabular}

\section{The parameters of simulated analysis}

\section{The selection of test parameters}

Area ratio $m$ was an important structure parameter of jet mixing apparatus [9-11], it expressed the ratio of mixed tube cross-sectional area and outlet cross-sectional area of jet nozzle, this paper adopted $\mathrm{m}$ as the area ratio. It was defined as follows equation. The values were shown in table 2 .

$$
m=\frac{A_{D}}{A_{d}}=\left(\frac{D}{d}\right)^{2}
$$

In the formula: $\mathrm{AD}$ and Ad expressed cross-sectional area of mixing tube and outlet crosssectional area jet-nozzle respectively, $\mathrm{mm} 2$.

$\mathrm{D}$ and d expressed cross-sectional diameter of mixing tube and outlet cross-sectional diameter of jet nozzle respectively, mm.

\section{The set of the structural parameters' value}

The purpose of this experiment is based on the characteristic of jet-mixing apparatus. The outlet diameters of jet-nozzle $\mathrm{d}$ and area ratios $\mathrm{m}$, and the main parameters were shown in table 2 . 
Table 2 Value of outlet diameter of jet-nozzle and area ratio

\begin{tabular}{cccccc}
\hline Structural parameters & \multicolumn{5}{c}{ Value } \\
\hline $\begin{array}{c}\text { Outlet diameters of } \\
\text { jet-nozzle } d / \mathrm{mm}\end{array}$ & 2 & 3 & 4 & & \\
Area ratios $m$ & 1.44 & 2.25 & 3.06 & 4.00 & 6.25 \\
\hline
\end{tabular}

\section{Simulated analysis}

\section{The simulation model}

Three-dimensional model of jet mixing apparatus was set up and imported into Fluent software to mesh before the numerical calculation. The physical model was meshed by ICEM software. The simulation calculation of turbulent model used the standard model.The medium of jet-mixing apparatus was water,and the parameter of water was the defined parameter in Fluent material database, $\rho=998.2^{\mathrm{kg} \cdot \mathrm{m}^{-3}}$ and dynamic viscosity $\mu=0.001 \mathrm{~kg} \cdot \mathrm{m}^{-1} \cdot \mathrm{s}^{-1}$. The computational domain for the inlet of working fluid was a certain distance of the section before the jet entrance, the difference in radial pressure was ignored. Set the entrance boundary of working fluid as the entrance condition. Set the entrance of injection fluid as entrance pressure boundary condition, the outlet of mixing fluid as outlet pressure and outlet boundary. The solid wall adopted a no slip wall as boundary condition.

\section{The set of boundary conditions}

The mixing principle of jet mixing apparatus was that the working fluid at high pressure and low speed driven by formed low pressure and high speed fluid through the nozzle, and then it took the indoor air to form a vacuum. Pesticide mother liquor was sucked in the effect of atmospheric pressure, two fluids were mixed in the mixing chamber, the energy was transmitted to the pesticide mother liquor. In the diffusion pipe section, the velocity of mixing fluid became smaller and the pressure of mixing fluid became higher.

The calculation was solved in Fluent of Ansys13.0 software and the solver used pressure solver. The numerical calculation used the method of finite volume which was the parameters of the convection term used two order upwind scheme, coupling mode of velocity and pressure used the SIMPLEC model, the accuracy of convergence was set to $10-4$. The wall used no slip conditions and the flow channel of jet mixing apparatus was managed by standard wall function treatment.

\section{The experimental scheme}

The initial set: the pressure of water entrance was $0.48 \mathrm{MPa}$, the pressure of pesticide was $0.1 \mathrm{MPa}$, the liquid flow rate was between $0.18 \mathrm{~m} / \mathrm{s}$ and $0.2 \mathrm{~m} / \mathrm{s}$. Then measure the mixing outlet pressure.

When the flow of the entrance liquid and pressure was controlled in a constant value, we could take the entrance pressure of water as variable, the initial entrance pressure of water was $0.48 \mathrm{MPa}$, with $0.02 \mathrm{Mpa}$ as a step then to test outlet pressure. The outlet pressure was tested at different combination with outlet parameters of jet-nozzle $\mathrm{d}$ and area ratio $\mathrm{m}$ and different pressures of water entrance. And the results was shown in figure 2.

The simulated results in figure 3 showed that outlet pressure roughly appeared linear change long with the change of the inlet pressure. In different combination of outlet diameter of jet nozzle and area ratio, the linear slope was different. The outlet flow had a large fluctuation caused by outlet pressure. 


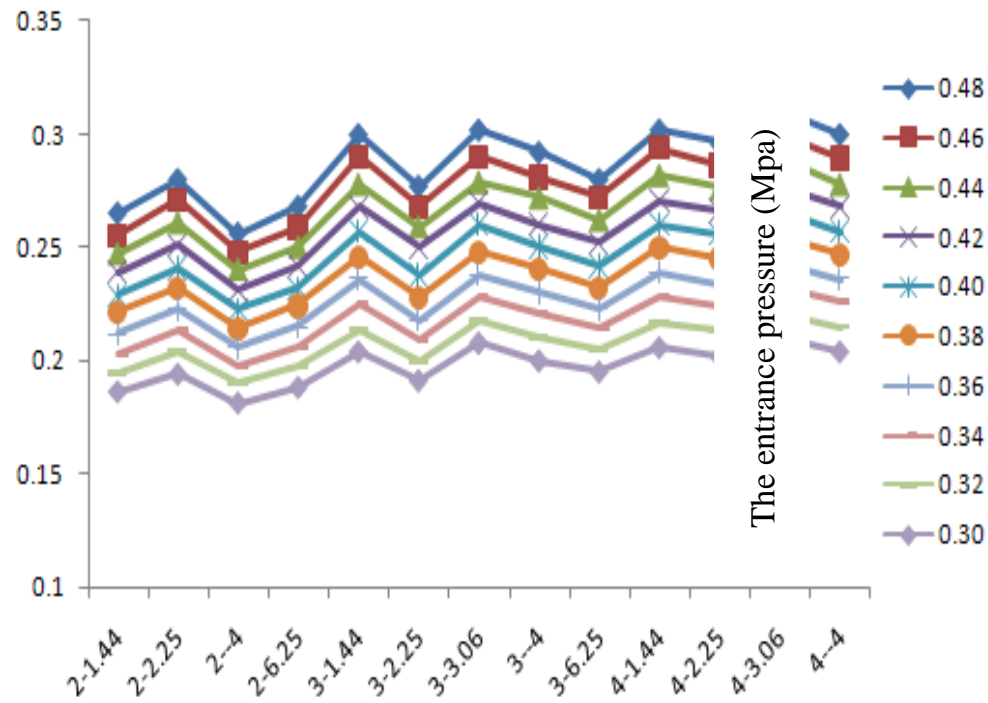

The outlet diameter of jet nozzle $d$-area ratio $m$

Figure 2 The results of outlet pressure tested

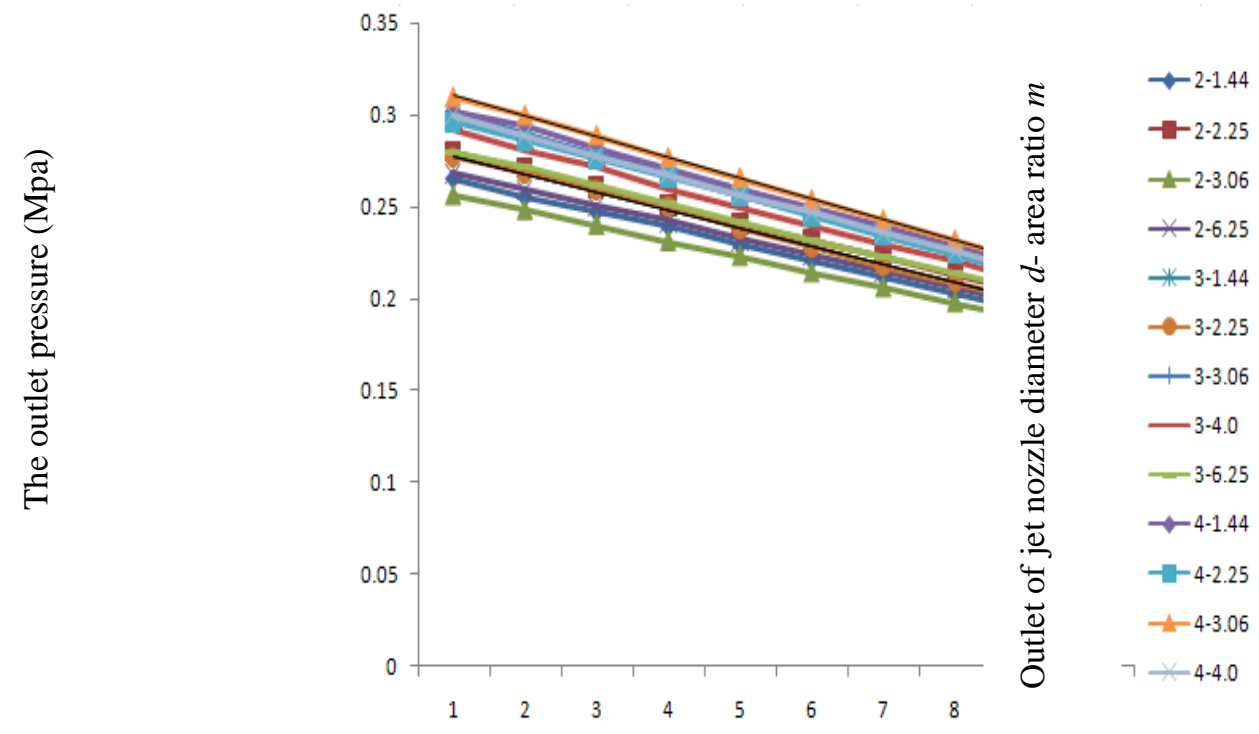

The number of times

Figure 3 The results of outlet pressure tested

\section{Conclusions}

From the simulation results, we could draw the conclusions (as shown below):

Firstly, in the condition of the same area ratio (such as $\mathrm{m}=1.44$ ), the less outlet diameter of jet nozzle $d$, the less outlet pressure was. Such as $d=2 \mathrm{~mm}$, the outlet pressure was less than others, and the wasted energy was larger than others.

Secondly, in the condition of outlet diameter of jet nozzle was $2 \mathrm{~mm}$, the mixing performance was best when area ratio was 2.25. In the condition of outlet diameter of jet nozzle was 3 , the mixing performance was better than others when area ratio was 1.44 or 3.06. In the condition of outlet diameter of jet nozzle was 4 , the mixing performance was better than others when area ratio was 1.44 or 3.06 .

Thirdly, comparing the outlet of jet nozzle diameters, we could find the mixing performance was better when the outlet diameter of jet nozzle was larger $(d=4)$.

From this experiment, in the experiment of jet mixing not only to consider the effect of area ratio but also to consider the effect of outlet of jet nozzle diameter. The wasted energy of jet nozzle 
nozzle also had a large proportion in jet-mixing apparatus.

\section{Acknowledgements}

This work was financially supported by The Project of National Natural Science Funds (31271620), Special Fund for Agro-scientific Research in the Public Interest (201203025-04), Agriculture Science Technology Achievement Transformation Fund (2014GB2C100295), Jiangsu Sci-Tech Support Plan for Agriculture (BE2014374), Jiangsu Sci-Tech Support Plan for Industry

(BE2014510).

\section{References}

[1] Vondricka J, Lammers P S. Real-time controlled direct injection system for precision farming[J]. Precision Agriculture, 2009, 10(5): 421-430.

[2] Vondricka J, Hloben P, Lammers P S. Optimization of direct nozzle injection system for sitespecific herbicide application[J]. An ASABE Meeting Presentation Paper Number: 071085. 2007.

[3] Langenakens J J, Climans L, Ramon H, et al. The effects of vertical sprayer boom movements on the uniformity of spray distribution[J]. Journal of Agricultural Engineering Research, 1999, 74:281 291.

[4] Chen Zhigang, Zhu Shuli, Qiu Baijing. Online jet mixing control system of pesticide concentration[J]. Journal of Drainage and Irrigation Machinery Engineering,2012,30(4): 463468.

[5] He Peijie,Wu Chundu,Chen Cuiying.The performance study on a new kind of spray mixing drug device[J] ,Transaction of the Chinese Society for Agricultural Machinery,2001,32（3）:44 47.

[6] Li Yanglin, Wu Chundu, Fu Ximin. Experimental study on two-stage jet mixing apparatus[J]. Transactions of the CSAE, 2008,24(1): 172-174.(in Chinese with English abstract)

[7] Qiu Baijing,Xu Xichao,Yang Ning.The simulation analysis of the influence of structure paraments on the mixing performance of jet mixing device[J],Transaction of the Chinese Society for Agricultural Machinery,2011, 42(6): 172 174.

[8] Xu Youlin,Zhou Fengfang,Guo Jingkun.Flow Field Simulation of Chemical Mixing Process for Direct Injection System based on CFD[C].2008:ASABE International Meeting,Rhode.

[9] Lu Hongqi. The Theory and Application of Jet Technology[M]. Wuhan: Wuhan University Press, 2004.

[10]Cheng Honggui, Long Xinping, Yang Xuelong, et al. Numerical and Experimental Investigation on a Super-large Area Ratio Pump[J]. Fluid Machinery, 2012, 40(7): 38-41, 51. (in Chinese with English abstract)

[11]Long Xinping, Zhu Jinmu. Hybrid finite analytical solution for confined coaxialjets of super small area ratio[J]. Engineering Journal of Wuhan University, 2003, 36(4): 1-5. (in Chinese with English abstract) 